\title{
TEMPERATURE EFFECT AND ITS ELIMINATION IN GEIGER-MÜLLER TUBE COUNTERS
}

\author{
By L. F. Curtiss
}

\section{ABSTRACT}

It has been found that in the usual form of the Geiger-Müller tube counter the rate of counting is affected by changes of temperature. The rate of counting, at a fixed potential applied to the tube, decreases as the temperature is increased. This indicates an increase in the density of the gas in the counter. Since it is hermetically sealed this can only be caused by evaporation of volatile material within the counter. The hard-rubber insulators commonly used in these counters are practically the sole source of such volatile material, consequently a form of counter has been devised in which only glass and metal are used and which does not have its rate of counting affected by changes of temperature.

\section{CONTENTS}

I. Introduction $\ldots \ldots$

II. Effect of temperature on usual form of counter

III. Description of improved counter

IV. Effect of temperature on improved counter. 231

V. Acknowledgments

\section{INTRODUCTION}

In the course of a study ${ }^{1}$ of the magnetic deviation of cosmic-ray particles, using Geiger-Müller tube counters, it was found that changes in the temperature of the counters affected their rate of counting. This effect may lead to erroneous results in experiments where precautions are not taken to maintain the temperature of the counters constant. The increasing use of these counters makes it desirable to have some knowledge of the cause of this behavior. Since it is frequently necessary to operate counters continuously over periods of several days, the elimination of this characteristic would greatly simplify the apparatus required if reliable results are to be obtained. This problem has been investigated and a form of counter devised which does not show a systematic change in rate of counting with changes of temperature.

\section{EFFECT OF TEMPERATURE ON THE USUAL FORM OF COUNTER}

The usual form of the Geiger-Müller tube counter consists of a metal tube with a wire stretched along its axis. This wire is supported at each end by insulating bushings fitted to the ends of the tube. The tube is exhausted to a pressure of a few centimeters of mercury, and

I B. S. Jour. Research, vol. 9 (RP509), p. 815, 1932.

$152894-33-6$ 
sealed. A high degree of insulation is not required, hence hard rubber is commonly used for these bushings.

Nearly all counters constructed as outlined above have been found to show a marked decrease in rate of counting when their temperature is raised. Although in some cases this variation was not sufficient to be detected when the temperature changed only a few degrees, more frequently even small changes produced a noticeable effect. In these cases an increase of about $15^{\circ}$ caused the counter to cease to function entirely. Almost without exception the original counting rate was observed on bringing the counter back to the original temperature.

An example of the change of the rate of counting with temperature for counters of this design is shown in Figure 1. The rate of counting is plotted against the temperature, the points indicated by open circles referring to the type of counter under discussion. In obtaining

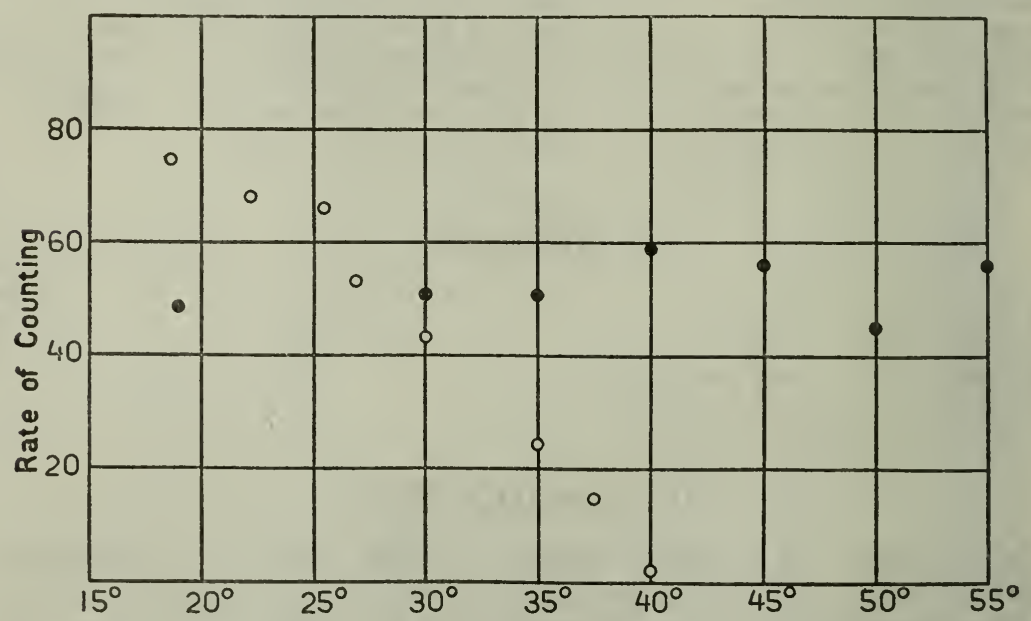

Temperature

FIGURE 1.-Graphical representation of the effect of changes of temperature on the average rate of counting of Geiger-Müller tube counters

O, previous form of counter with hard-rubber bushings.

, improved form made entirely of glass and metal.

these data, care was taken to maintain the voltage applied to the tube constant to within one-half of 1 per cent. As the graph reveals, this counter, which was counting at an average rate of about 70 per minute at $19^{\circ}$, ceased to count entirely at $40^{\circ}$. The variation of even a few degrees in the neighborhood of $20^{\circ}$ had an observable effect on its rate.

This is what is to be expected if the pressure in the counter had been increased by permitting additional air to enter, thus increasing the density of the air in the counter. In the case of a sealed counter, however, no additional air can enter. The natural explanation for this increase in density is that volatile material is present in the counter. The only apparent source of this material is the insulating bushings. Accordingly, a form of counter was constructed in which only glass and metal were used. 


\section{DESCRIPTION OF IMPROVED COUNTER}

To avoid the use of a metal tube which might be contaminated with volatile substances, a copper tube was out-gassed in a vacuum furnace and used for the tubular part of the counter. Metal bushings were soldered into the ends of the copper tube to support pyrexcopper seals, $C C$, as shown in Figure 2, which represents a cross section of a completed counter. To shield the central wire from the adjacent metal parts at the ends, glass sleeves, $G G$, were sealed in as shown. They insure that electrical discharges occur only in the main volume of the counter. In assembling the counter, the wire with tungsten lead attached was inserted at the end, $S$, while still open, and the tungsten lead was sealed in at $T$, sufficient tension being put on the spring inside the sleeve at the opposite end to make certain that the wire will remain taut. The counter was attached to a pump, evacuated to the desired pressure, and then permanently sealed by closing the pyrex tube at $S$ by means of a flame. This makes a more rugged counter than the former glass-inclosed types. It is particularly easy to arrange these counters in line for coincidence counting since the tubular part of the counter is directly visible.

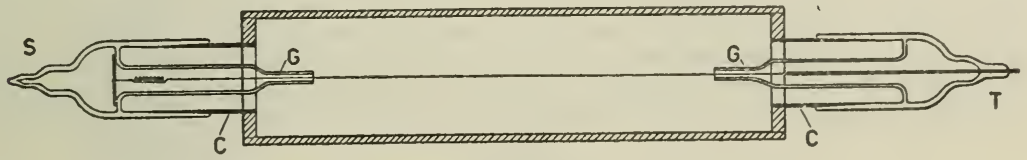

FIGURE 2.-Cross section of improved counter

\section{EFFECT OF TEMPERATURE ON IMPROVED COUNTER}

If the hypothesis is correct that the change in counting rate observed in the earlier type of counters with changes in temperature is caused by vapors from the insulating material, the improved form should not show this effect. The rate of counting of one of these glassmetal counters was observed at various temperatures to see whether the variation had been eliminated.

A counter, constructed as described above and filled with dried air, was used in this test. It was operated at a constant voltage and the temperature was changed by steps of a few degrees. The results are represented in the graph in Figure 1 by the solid dots. Although there is some variation in the rate due to statistical fluctuationseach dot represents a 5-minute average-it is clear that there is no effect of temperature up to $55^{\circ}$. This is a greater range of temperature than is usually encountered in the use of the counter. It is quite safe to assume, therefore, that, for fluctuations of several degrees in the neighborhood of room temperature, there is no change in the counting rate attributable to changes in temperature. This feature is of considerable advantage in experiments in which automatic registration is carried on over long periods of time. Under such conditions it is impossible to maintain counters at a constant tem- 
perature without some form of thermostatic control which often introduces troublesome complications.

\section{ACKNOWLEDGMENTS}

The writer wishes to thank L. L. Stockman and B. W. Brown for help in constructing and testing various designs of counters.

Washington, December 8, 1932. 